\title{
Risco e saúde reprodutiva: a percepção dos homens de camadas populares
}

\author{
Reproductive health and risk as perceived \\ by low-income Brazilian men
}

\footnotetext{
1 Faculdade de Serviço Social, Universidade do Estado do Rio de Janeiro. Rua São Francisco Xavier 524, Bloco D, Rio de Janeiro, RJ 20550-013, Brasil. 2 Instituto de Filosofia e Ciências Humanas, Universidade Estadual de Campinas. Cidade Universitária Zeferino Vaz, C. P. 6110, Campinas, SP

13081-970, Brasil. caralmeida@uol.com.br
}

\begin{abstract}
Studies in the field of reproductive health discuss existing gaps in traditional research models, which neglect not only social and cultural aspects but also ethical and philosophical ones. Such aspects cut cross over the definition of essential themes for reproductive health research, like sexuality, reproduction, and gender. The search for connections between the two disciplines (Social Science and Public Health) relates to how people and social groups limit and deal with the risks they face. In this study, we analyze the perception of risk in reproductive health among a group of low-income men from Rio de Janeiro. The group was intervi ewed during a study on male contraception. The objective was to identify the si tuations and contexts from which the problem (and the contents ascribed to it) emerge. One can conclude from the interviews that there is a risk hierarchy which is modified according to cultural values and relational, institutional, and social contexts.
\end{abstract}

Key words Reproductive Medicine; Risk; Gender; Adult Health

Resumo Os estudos desenvolvidos na saúde reprodutiva discutem, entre outras coisas, as lacunas exi stentes nos model os tradi cionais de pesquisa, os quais negl igenciam aspectos sócio-culturais e também ético-fil osófi cos. Estes aspectos atravessam a defini ção de temas essenci ais à pesquisa em saú de reprodutiva, tais como: sexualidade, reprodução e gênero. A busca da articulação entre as duas disci plinas (Ciências Sociais e Saúde Pública) ajuda a pensar como as pessoas e os grupos sociais del imitam e percebem os riscos que enfrentam. Neste estudo, analisamos a percepção de risco em saúde reprodutiva de um grupo de homens de camadas populares do Rio de Janei ro, entrevistados no âmbito de uma pesquisa sobre contracepção. Visamos identificar as si tuações e os contextos em que o problema emerge e o conteúdo atribuído ao mesmo. A partir desses depoi mentos, é possível concluir que existe uma hierarquia de riscos entre os entrevistados, a qual é modificada dependendo de valores culturais, contextos relacionais, institucionais e sociais.

Palavras-chave Saúde Reprodutiva; Risco; Gênero; Saúde do Adulto 
Este trabalho é fruto de uma pesquisa que contou com o apoio da FAPERJ (Fundação de Amparo à Pesquisa do Estado do Rio de Janeiro) e foi realizada junto a homens de camadas populares, cujo objetivo era refletir sobre o lugar destes na reprodução, em particular na contracepção. As entrevistas, no total de 27, foram feitas numa maternidade pública do Rio de Janeiro, no período de janeiro a junho de 1999, com duração média de 45 minutos e seguiram um roteiro que abordava os seguintes temas: rotina familiar/ atividades domésticas, paternidade, contracepção e sexualidade. Todos os depoimentos foram tomados sem a presença das esposas e em diferentes situações: quando os homens acompanhavam as parceiras nas consultas de pré-natal, no atendimento de pósparto ou quando as visitavam na ocasião do nascimento do bebê. Os homens atendiam ao seguinte perfil: estavam em união, na faixa etária adulta e possuíam pelo menos um filho. Houve boa receptividade do trabalho de pesquisa.

A idade média é de 32 anos, 78\% mora em áreas de concentração de pessoas com menor poder aquisitivo no Rio de Janeiro (45\% zona norte, $22 \%$ zona central e $11 \%$ Baixada Fluminense), alguns são moradores de favelas nessas regiões e a renda mensal média é em torno de $\mathrm{R} \$ 500,00$. As atividades profissionais são do setor informal de serviços e $37 \%$ das esposas estavam trabalhando, no momento da entrevista, em ocupações como: empregada doméstica, técnica de arquivo, costureira, vendedora de rendas de fabricação própria e cozinheira. Cabe destacar que, muitos relatam a realização de atividades profissionais em horários flexíveis e/ ou que implicam na conjugação geográfica dos espaços da casa e do trabalho, favorecendo uma interação maior com a rotina doméstica. $30 \%$ dos homens referem não possuir o 10 grau completo. Identificam-se como "morenos" ou "brancos" e, apesar de nascidos na cidade do Rio de Janeiro, há uma forte presença, entre os homens que entrevistei, da experiência migratória do interior dos estados do Nordeste, com uma expectativa de salário meIhor e posterior regresso aos locais de origem. A grande maioria possui dois filhos, mas cabe lembrar que uma parte dos informantes estava vivenciando a situação do nascimento de mais uma criança. É relevante a presença de filhos não consangüíneos na composição de suas famílias e explicitam o desejo de terem o "filho de sangue".

Antes de passar à descrição dos dados, gostaria de fazer algumas considerações sobre a noção de risco nas Ciências Sociais e na Saúde
Pública. Nesse sentido, cabe dizer que o conceito ganha diferentes conotações em cada campo, tendo em vista a história e a natureza das disciplinas.

Na Saúde Pública, o conceito desenvolveuse a partir dos aportes fornecidos pela epidemiologia e caminhou junto com o problema da epidemia da AIDS. Isso trouxe conseqüências para os estudos desenvolvidos na área da saúde reprodutiva, que apresentaram lacunas metodológicas - pouca incorporação de estudos de natureza qualitativa - e conceituais. Com respeito a este último aspecto, Parker (1995) aponta para a não problematização das categorias utilizadas nessas pesquisas, como foi o caso do tema da "sexualidade".

Além desse problema, a perspectiva do risco, associada à epidemia da AIDS, trouxe um conteúdo moral e estigmatizante para os estudos no campo. Um balanço da história da assimilação do conceito nas pesquisas sobre AIDS, pode ser encontrado no trabal ho de Ayres et al. (1999), cabendo registrar aqui, apenas, que o mesmo evoluiu de uma proposta centrada nos fatores de risco, comportamento e grupos de risco para uma noção mais recente de "vulnerabilidade". Nessa última abordagem, a perspectiva é a de tomar em conta as particularidades sociais, políticas, culturais e subjetivas que interagem com determinadas situações de adoecimento.

No que se refere ao campo das Ciências Sociais, o debate ganha fôlego nas últimas décadas, com as formulações de Giddens et al. (1997) sobre o esgotamento da sociedade industrial e o surgimento da sociedade de risco, cuja dinâmica estaria centrada nos avanços tecnológicos do final do século XX. Não vamos nos aprofundar neste tema, embora o mesmo forneça um conjunto de problemas sobre a natureza, a natureza humana e a própria questão da reprodução, cujas implicações são extremamente importantes para os estudos em saúde reprodutiva. Em outro sentido, mas ainda no âmbito das Ciências Sociais, encontramos os estudos de Mary Douglas sobre risco (Douglas, 1990; Douglas \& Wildavsky, 1982), perigo, corpo e natureza (Douglas, 1970) com enfoque na idéia da percepção do risco.

Para a autora, as escolhas e posições assumidas pelas pessoas estão diretamente relacionadas à sociedade, de modo que a percepção do risco é um processo social em que cada sociedade realiza suas combinações sobre medo e confiança. Em seu estudo Risk and Culture, Douglas \& Wildavsky (1982) discutem a idéia de que os riscos são socialmente selecionados e não uma evidência natural ou física. Por que 
e como tipos particulares de perigo vêm à tona e outros não? Pergunta a autora. Sua resposta é que os escolhemos no mesmo "pacote em que escol hemos nossas institui ções sociais" (Douglas \&Wildavsky, 1982:9). Assim, se para uns, os perigos maiores são de natureza física, como poluição; para outros, o problema é de ordem social, como por exemplo, inflação e desemprego.

A seleção de uma hierarquia de riscos a serem enfrentados, diz respeito a questões de natureza política, de modo que este argumento é um contraponto a uma perspectiva que toma o risco como algo que emerge natural mente, numa espécie de evolução da sociedade. Assim, a reflexão proposta pela autora permite discutir o substrato social e cultural das experiências corporais, dentre as quais poderíamos relacionar o adoecimento pelo HIV/AIDS, as situações que envolvem a reprodução e a vivência da sexualidade. Por trás dos simbolismos atribuídos a cada um desses eventos e da percepção de risco das pessoas e grupos envolvidos, fica a pergunta: Quais relações sociais e valores culturais, que particularizam cada sociedade, ajudam a explicar essas experiências?

\section{Casamento e família: "tentando fazer o meu mundinho"}

Embora o objetivo da pesquisa não tenha sido pensar a questão do risco - não há nenhuma pergunta específica no roteiro de entrevistas a este respeito - o tema emergiu de forma espontânea no decorrer das histórias que os homens contavam sobre suas práticas reprodutivas e não-reprodutivas. Assim, algumas situações são claramente classificadas como de risco, dentre as quais encontrei aquelas vinculadas à aquisição do HIV/ AIDS. Outras questões relativas à saúde reprodutiva (gravidez, nascimento dos filhos, contracepção) são nomeadas com expressões diversas, tais como: perigo, medo, temor, receio e, a mais comum, preocupação.

De um modo geral, posso afirmar que a idéia de contrair doenças (sexualmente transmissíveis, AIDS) é a mais recorrente quando expressam a noção de risco. Neste caso, o casamento aparece como um demarcador de exposição/não exposição ao mesmo. Sr. José, por exemplo, afirma que "vida de solteiro é arriscada", o que justifica o fato de ele ter buscado logo uma vida em família assim que chegou ao Rio de Janeiro. Para alguns homens que entrevistei, a situação de estar solteiro configura um risco. Mário explica que a delimitação da experiência sexual ao casamento trouxe-Ihe uma vivência de segurança.
“O sexo pra mim, há muitos anos atrás, quando eu era mais novo[...], eu via assim como [...] tesão, aquel a coi sa gostosa, né? Hoj e também não deixa de ser, mas só que hoje eu tenho muito mais segurança no sexo, né, porque antigamente... se dizia assim: que o sexo bom era o sexo de rua, era o sexo que se fazia lá fora, e eu até acreditava nisso, né? E hojenão, hojeeu vejo que o sexo legal mesmo é o sexo com a pessoa que você ama, com a pessoa que você tem do seu lado, sabe, porque te dá segurança [...]Hoje eu não me vejo capaz detrair a minha mulher na rua com outra... com mulher nenhuma por mais bela que ela seja, por mais apresentável que ela seja, porque nós sabemos muito bem que hoje existem muitas doenças, né, doenças irreversíveis como a AIDS, que não tem remédio, que não tem cura. [...] Não consigo ter tipo de relação nenhuma na rua; mais pelo medo, por aquela responsabilidade de você saber que [...] vocêtem uma boa esposa, que vocêtem um fiIho, sabe? Eu não me perdoaria, acho queeu me suicidaria, [...] se um dia eu faltasse com isso..." (grifos meus).

Também para Manoel, Tadeu, Lúcio, Márcio, Lauro, Vinícius o problema está fora de casa, nas relações com mulheres da rua e vem de fora para dentro. Estas oposições dentro/fora, casa/ rua são muito utilizadas para caracterizar a diferença entre estar em risco/ não estar em risco, como também aparecem nos trabalhos de Goldenberg (1995), Sarti (1996), Guimarães (1996) e Knauth (1999). As experiências com relações extraconjugais são consideradas situações de fora a cujas implicações boa parte dos entrevistados não se sente exposto, pois não se inclui no grupo dos que têm mulher fora. Márcio, por sua vez, relata que só teve uma experiência extraconjugal, assim mesmo porque estava fora de si - "bebida efesta do trabaIho" - e depois, nunca mais isso ocorreu.

Marcos, Rodrigo, Vinícius e Mário contam que com o casamento estabeleceram uma relação de exclusividade e fizeram uma espécie de pacto defidelidadecom as esposas. Perguntei a Marcos se ele fazia algo para evitar filhos, e este, referindo-se ao fato de não usar camisinha respondeu:

“Não[... ]não faço nada pra estragar a minha conduta aí fora. Não sou santinho não, não existe, eu até só faço o possível... eu não sou santo, mas não procuro [...] fizemos um pacto, um pacto de fidelidade e estamos levando a vida bem melhor. Ela não tem ninguém e eu também não tenho ninguém, até quando Deus quiser e assim está feito o nosso pacto".

Em relação ao uso da camisinha, pude observar uma dificuldade da mesma ser introdu- 
zida na relação do casal, em geral, associada à idéia de que é algo provisório no casamento, deve ser usada quando solteiro ou em relações não duradouras. O casamento é, portanto, uma espécie de libertação de algo que, para a maioria dos entrevistados, incomoda, impede o contato natural entre os dois sexos. Mário expressa uma idéia de que a família constituiu para ele a separação entre dois mundos, o que é avaliado como algo melhor.

“E num mundo hoje muito mais perigoso, muito mais cheio de fagulhas, muito mais cheio de conseqüências, né [...] eu acredi to que essas coisas, devido a essa liberação, [...] estão se perdendo, sabe? As coisas estão tomando um rumo [...] que eu acho que não élegal [...] Então, por isso que eu tô me fechando mais pra minha esposa, pros meus filhos e tô tentando fazer o meu mundinho com a cabeça do jeito que eu te nho, do jeito queeu penso..." (grifos meus).

Para Fábio e Nilton, não é exatamente o casamento que define uma conduta mais segura, mas o nascimento dos filhos. Em ambos os casos esse acontecimento significou uma mudança na vida, que eles consideram para meIhor, "sem bares, festas sozinhos efarras".

Ainda em relação às doenças sexuais e a AIDS, alguns entrevistados apresentam uma idéia de que possuem dispositivos de avaliação sobre se podem ou não arriscar a sorte tendo uma relação sexual fora do (casa)mento. Assim, para Fábio, "é pegar uma mulher limpinha, cheirosa, educada". O trabalho de Gogna \& Ramos (1999), sobre crenças de homens e mulheres adultas a respeito de prevenção de doenças sexualmente transmissíveis, também enfatiza a higiene como fator importante descrito pelos homens para a aquisição de tais doenças e para a identificação de situações de riscos.

Tornando um pouco mais complexo esse modelo higiênico do corpo, Jonas conta que hoje é "tudo muito confuso", referindo-se às experiências sexuais dos rapazes. Afirma não se sentir em risco, pois é uma pessoa muito parada e só sai quando conhece a mulher. Embora seu discurso não esclareça com precisão o tipo de conhecimento requerido, para ele essa é uma atitude cautel osa.

A pesquisa de Gogna \& Ramos (1999) citada acima, encontrou que os homens enfatizam a idéia da mulher de confiança (dona de casa em oposição a outra de vida sexual muito ativa) para estabelecerem seus critérios de segurança, enquanto as mulheres precisam de um histórico maior do parceiro - "conhecendo bem a pessoa". Apesar disso, as autoras consideram que as "estratégias de seleção" tendem a ser acionadas pelos homens, visto que as mulhe- res se inclinam para uma lógica baseada em "estratégias de proteção" (acham que os homens devem usar preservativo apenas em relações extraconjugais), utilizando uma classificação sugerida por Pollack.

Transcrevo, a seguir, um trecho do depoimento de Sílvio, o qual indica, de maneira muito significativa, os critérios adotados por ele e por amigos para controlar as situações de risco que vivenciavam no passado. $O$ entrevistado relata as estratégias que adotava, em sua vida de solteiro, para avaliar uma possível exposição a riscos nos encontros sexuais.

“Eu até peguei algum risco com algumas parceiras [...] no tempo quando era soltei ro.[...] Com algumas parceiras eu real mente não corria o risco... por [...]... conhecimento, de vocêconhecer numa noite [...] ou numa praia, edepois marcar um encontro à noite. Eu sempre me precavia, mas com determi nadas parceiras a gente até corre esse risco [...] porque a gente faz uma análise de repente pela experiência, pela vivência, de que realmente aquela pessoa possa não estar infectada e, em al guns casos, a gente até assume, né? No caso de já estar com 59 anos, [...] é uma coisa que vai acontecer pro futuro eaté lá já vou estar morto. (Risos)[...] Às vezes [...] nem éo ambiente, éo ti po da pessoa, né? É o modo dela agir, a educação que você nota na pessoa, o papo que a gente leva ..." (grifos meus).

Cabe destacar nesse depoimento, que Sílvio afirma possuir um controle sobre a situação, valendo-se de al gumas qualidades subjetivas como maturidade, conhecimento e experiência, como também ocorre nos depoimentos das pesquisas com mulheres de Guimarães (1996) e com homens e mulheres de Loyola (1994) e de Gogna (1998).

Olavarría (1999), na sua investigação com homens heterossexuais em Santiago do Chile, que vivem com companheiras ou esposas em torno da construção de identidades masculinas e relações de poder entre os casais, observou a importância do pai para o aprendizado masculino sobre os cuidados que deveriam adotar na escolha de uma mulher para fazer sexo. Para o autor, esse aprendizado é mais comum entre os setores populares, cujos pais "socializaram seus fil hos no uso do poder em relação à sexual idade e mostraram a el es o jogo da negociação com a companheira, a partir de uma posição de domínio" (Olavarría, 1999:160). Para os homens que ouvi, o casamento constitui uma instância muito segura na medida que está sob o poder masculino (deles), a decisão sobre assumir algum risco, que neste caso, consiste no risco de ter relações sexuais sem camisinha. Tal posição indica que os homens 
estariam investidos de um lugar de autoridade na vida conjugal e na família.

O depoimento de Sílvio ilustra bem a importância da conversa e do conhecimento do outro para se ter alguma segurança na prática sexual. O entrevistado relata esta situação quando conheceu a esposa atual.

“... ficamos batendo papo ali até de noite. Ela mefalou da vida dela, eu falei da minha e tal. Então, quando nós tivemos a primeira relação, [não usamos] camisinha nem nada e a partir daí nós nunca usamos praticamente, né? Então sei lá, é uma coisa que você ol ha ediz: 'Não, com aquela ali eu vou correr risco real mente'. [...] Não estamos falando de profissionais do sexo [...], lá no fundo até são, né, de outra forma. Não recebem dinhei ro, mas sempre vêem a situação pra lanchar, pra comer, [...] são pessoas que às vezes podem aténão trabal har. A orla de Copacabana é[...] cheia disso e cabea você, pela experiência e pela maturidade, discernir quem é quem, não é? Claro quea gente às vezes pode se dar mal, mas via de regra... eu sempre me senti seguro" (grifos meus).

A idéia de que o casamento é uma segurança para os homens com quem conversei, pois estaria sob o controle deles a sel eção das relações sexuais, parece caracterizar a extraconjugalidade como uma experiência masculina. Não se evidencia nos depoimentos colhidos, qualquer sentimento sobre uma possível relação sexual das esposas "fora" do casamento. Nesse sentido, vale a afirmação de que a experimentação sexual é da natureza masculina e que a extraconjugalidade dos homens é aceita tacitamente entre os pares, e até mesmo pelas mulheres, como evidenciou o estudo de Heilborn \& Gouveia (1999) sobre sexualidade em mulheres populares no contexto da AIDS, ea análise de Knauth (1999) para o caso da legitimidade da contaminação feminina pelo HIV/ AIDS ocorrida através dos parceiros.

Embora meu grupo de entrevistados não se sinta sob risco, mesmo tendo relações fora do casamento e sem camisinha, conforme eles próprios classificam as situações de vulnerabilidade às doenças sexuais, alguns depoimentos expressam um alívio quando as esposas fazem o teste anti-HIV, na ocasião da gravidez, como é o caso de Rodrigo e Lúcio.

Nesse conjunto de situações, nas quais os informantes avaliam a existência ou não de risco, este conceito aparece estreitamente vinculado ao comportamento. Assim, comportar-se de forma diferente pode ser a garantia para sentir-se fora de perigo. Na medida em que cada um controla, à sua maneira, seu comportamento de risco - relações sexuais "fora" do ca- samento sem o uso do preservativo - o mesmo, aparentemente, deixa de fazer parte de suas vidas. Entretanto, a situação de real ização do exame anti-HIV parece indicar uma ambigüidade: a presença silenciosa do risco.

\section{Construindo uma hierarquia de riscos em saúde reprodutiva}

A idéia de risco na saúde reprodutiva, não apareceu ligada apenas à possibilidade de contrair AIDS ou doenças sexualmente transmissíveis nos depoimentos ouvidos. Encontrei, é verdade, que de forma bem menos enfática, sentimentos de preocupação, medo ou perigo atribuídos à vivência da contracepção, da gravidez e do nascimento dos filhos.

No primeiro caso, o da contracepção, os entrevistados contam que a preocupação de não engravidar atrapalha a prática sexual. Orlando chega a explicar que o medo de engravidar causa impotência sexual.

“Atrapal hava muito [...]... porque o sexo é vocêtá...com a sua mentelivre, né, você não pode ter preocupações, vocêtem que... se dedicar aquele momento, só a você, só... a sua cabeça tem que tá ligada naquele momento ali ... E você fica com medo e o medo causa... [...] impotência... Na hora da ejaculação, por exemplo,[... ... bati a aquele medo; de repente vinha na minha cabeça quenão podia, entendeu?"

Sandro, Lauro, Tadeu e Denilson também parecem identificar que a prática de evitar fiIhos constitui uma preocupação e, em contrapartida, a contracepção pode ser encarada como uma segurança. Denilson se diferencia dos demais porque a idéia de realizar a regulação da fecundidade foi motivo de sua preocupação somente enquanto esteve solteiro, já que com o casamento seu desejo de ter filhos pôde se expressar livremente.

Contudo, a contracepção guarda outros riscos. Os métodos utilizados também podem ser percebidos como inseguros por alguns entrevistados. A camisinha, por exemplo, pode estourar, afirmam Vinícius e Lauro, "tirar a potência" ou fazer "perder a ereção"; a pílula, pode ser de farinha, diz Tadeu. A ligadura, por sua vez, é motivo de preocupação de Lúcio, pois a mãe de sua esposa perdeu um rim quando fez a operação. Embora os homens que ouvi revelem que a prática contraceptiva corrente é baseada no uso de hormônios (pílula anticoncepcional e injeção hormonal), e a considerem mais segura que os outros métodos, reconhecem que os hormônios podem trazer problemas à saúde. 
Portanto, no que diz respeito à contracepção, os riscos parecem estar associados à saúde em geral, à performance sexual e à tecnologia contraceptiva, e, não se revestem do conteúdo comportamental presente na questão das doenças sexualmente transmissíveis e da AIDS.

O estado gestacional também foi evidenciado e é classificado por Sandro como perigoso; enquanto na situação de Rodrigo, o medo da gravidez ocorre devido ao fato da esposa possuir idadeavançada. Para Sandro, o medo estava relacionado de modo mais genérico à:

“[...] saú de da Sueli, no caso se ia correr tudo bem porque... não vou generalizar, né, mas hoje em dia a gravidez de uma mulher é muito perigosa né? Se não tiver cuidados né, se não tiver bem assistida. Então, sempreprocurei acompanhá-la em tudo [...] o médico até já me conhecia".

Nesse depoimento, o risco é remetido ao tipo de assistência à saúde, especialmente em um momento considerado crítico, como é o caso da gestação. Outra situação reconhecida como vulnerável no contexto do atendimento em saúde, é a do nascimento dos filhos. Orlando revela preocupação e medo com o parto e o nascimento do bebê, o que o levou a criar estratégias para garantir o acompanhamento do médico que Ihes daria maior confiança. Ambas as falas se dirigem à situação do atendimento público em saúde reprodutiva, indicando uma espécie de vulnerabilidade social (Ayres et al., 1999) a cujas implicações os homens sentemse submetidos.

“...a gente tinha muita preocupação com re lação ao parto [...] A gente pega no jornal muita notícia aí decrianças morrendo por falta decuidado... devido à Maternidade, pegar infecção, um monte de coisa, roubo de criança, sabe? Então, a gente tinha [...] muito medo porque... a gente vêmuita coi sa ruim, né? Então, consegui contato com o Dr. Júlio, eaí vim aqui e conversei com ele... os últimos quatro meses foi el e quem acompanhou, entendeu? E foi marcado pra nascer no dia em que ele estivesse de serviço".

Outro informante, Dirceu, mostrou apreensão com a possibilidade do bebê nascer com problemas, medo este originado na experiência familiar de histórias de crianças com paralisia infantil. Nesse caso, a percepção do risco está vinculada à uma possível herança genética, classificada por ele como perigosa e relacionada ao seu grupo de origem.

"Tava muito preocupado com a gravidez dela.[...] É porque [...] tenho um irmão que tem paral isia infantil, né, na [família] dela também. Isso aí ficou na minha cabeça o tempo todo. [...] Eu ainda tô preocupado porque ainda não vi ela de olhos abertos. Eu perguntei até: Ela já abriu os olhinhos? Claro que já. Vocêtem certeza? Claro quejá".

Um dos depoimentos colhidos, coloca a própria decisão de ter filhos na lista dos riscos a serem enfrentados. Nessa situação, parece que entra em jogo uma certa definição da identidade do gênero masculino, a qual implica uma idéia de responsabilidade pelas demandas advindas da criação e pela garantia de segurança dos filhos, cuja efetivação é quase impossível de ser concretizada no contexto social e urbano em que vivem as camadas populares. Arilha (1998), trabalha bem essa noção da responsabilidade como atributo masculino frente à família, e Sarti (1996), destaca o código de honra envolvido no papel do homem-pai nas famílias pobres. É Sílvio quem afirma:

“É uma responsabilidade maior, né? Tanto que agora eu casei e... até nos mudamos para perto dos familiares dela; ela é do interior de Minas, e eu sempre falei que não queria outro filho nessa cidade porque aqui é muito difícil pra gente conseguir as coisas. Aqui no Rio, é muito bom quando vocêestá numa situação financeira muito boa, porque pra tudo que você faz, vocêtem queter dinheiro pra gastar, écondução, éo ir evir, né? É comer fora [...], éum médico, é uma coisa e outra. E a vida no interior é uma vida mais tranqüila, e eu que já tive fiIhos... sempre nos primei ros anos, é realmente um sacrifício muito grande dos pais, é aquela eterna vi gi lância, o risco de médico, de passar mal, uma coisa e outra. Então, a gente tá até pretendendo ir talvez lá pro interior de Minas".

No conjunto das situações percebidas com o rótulo de risco pelos entrevistados, encontramos uma predominância daquelas vinculadas à contaminação a doenças sexuais. A contracepção e a gravidez aparecem apenas em alguns depoimentos. Contudo, quando falam da educação dos filhos, e especialmente das fiIhas, outros riscos em saú de reprodutiva passam a ser considerados. A gravidez é considerada um problema importante, juntamente com as doenças e a AIDS, o que leva os pais a se preocuparem em realizar uma espécie de vigilância mais intensa sobre as meninas. Também aparecem afirmações que revelam a maior preocupação em fornecer informações às meninas, na ocasião da menstruação, que funcionem como advertências para os riscos a que elas estão expostas.

Além desses temas, surge ainda o problema da violência sexual, conforme afirma Aluísio:

“Hoje vocênão tem só a questão pra engravidar, hoje vocêtem as doenças, vocêtem a maldade, a perversidade no mundo para com as 
meninas né? [...] Vários casos de estupros, de se qüestros, geralmente de $90,10 \%$ dessa situação é com homens o resto étudo mulher".

Um assunto que só é destacado como risco quando pensam sobre os seus filhos, diz respeito à orientação sexual. Para Lúcio,

“... o pai tem que ir testando a criança de toda forma, até a sexuali dade mesmo, esse negócio de beijo na boca. Tentar... não dar uma má pessoa. O que adianta você [ser] uma pessoa estudiosa e ser um homossexual ou uma pessoa... sapatão, como se diz, né, no futuro?"

Além disso, as pessoas entrevistadas identificam situações de riscos que não estão associadas à questão da saúde reprodutiva em sentido estrito. Dentre elas, é possível citar aquelas relacionadas ao tipo de trabal ho com o qual os homens estão envolvidos - um policial, um metalúrgico que lida com produto de responsabilidade - e outros riscos ligados ao local de moradia, que lhes coloca frente a situações de violência e morte que terão de administrar durante a criação dos filhos. Além desses depoimentos, encontrei o de Adriano, que traz uma história de vida marcada pelo risco constante de se tornar um marginal.

Apesar desses discursos levantarem aspectos sociais mais amplos, que parecem concorrer com a percepção de risco em saúde reprodutiva, não foi possível determinar com precisão a relação entre os tipos de riscos veiculados, como pude observar na leitura de outros trabalhos de pesquisa. Knauth (1999), por exemplo, revela que a AIDS é secundária para as mulheres casadas soropositivas de camadas populares, que al ém de colocarem em primeiro plano os parceiros, familiares e filhos convivem com insegurança, morte, incerteza do alimento, do trabalho e moradia. É delas a afirmação de que "se pode morrer de qual quer outra coisa" (Kanauth, 1999:134). Também Heilborn \& Gouveia (1999), relatam uma espécie de minimização dos riscos da AIDS em função do contexto social em que vivem as mulheres de camadas populares que fizeram parte de seu estudo. Guimarães (1996), reafirma a importância desses argumentos para a manutenção da AIDS como uma doença do "outro", al go que estaria à distância das mulheres de sua pesquisa. A autora avalia que “... assegurar a masculinidade, a feminilidade, o trabalho, a vida afetiva e os Iaços famili ares certamente col oca-se no patamar mais al to da hierarquia deriscose perdas pessoais" (Guimarães, 1996:315).

Os trabal hos citados acima, enfocam especialmente o problema da AIDS e o gênero feminino, meu estudo, ao contrário, centrou-se na abordagem da dinâmica de gênero no campo da regulação da fertilidade. Desse modo, meu material não visou explorar em profundidade a categoria risco, minha intenção com esse artigo foi ressaltar que, neste grupo, muito embora os homens falem de uma boa hora e da necessidade de planejamento para terem filhos, tal evento não inspira uma visão de risco na relação sexual. Esta concepção, por sua vez, é fundamental para os estudos voltados ao tema da contaminação pelo HIV/ AIDS e estratégias de prevenção.

Todavia, posso afirmar junto com as demais pesquisas, que a percepção de risco dos homens que entrevistei é minimizada mediante certos valores culturais diretamente atribuídos ao gênero masculino. Assim, ainda que se reconheçam vulneráveis à contaminação de doenças sexuais e AIDS no contexto de relações extraconjugais sem uso do preservativo, tal percepção é atenuada mediante a valorização de características que seriam típicas ao gênero masculino: vivência pessoal na prática da seleção de parceiras ( a experimentação sexual) e a idéia de que a extraconjugalidade é uma experiência primordialmente dos homens.

\section{Levantando novas questões: riscos e contexto sócio-cultural}

Refletindo sobre a representação de risco para esse grupo, considero que a mesma não está limitada ao comportamento, embora este tenha um papel importante na classificação que os entrevistados fazem sobre algumas situações, como é o caso da aquisição de doenças sexualmente transmissíveis e da AIDS. Entretanto, encontrei idéias de risco associadas tanto a estados de vulnerabilidade pessoal quanto social - locais de moradia, instituições, tipo de assistência e tecnologias disponíveis em saúde reprodutiva.

Observei uma diferença significativa de ênfase nas situações vividas pelos entrevistados. As doenças sexualmente transmissíveis e a AIDS são percebidas como riscos, ao passo que outros temas da saúde reprodutiva, tais como, gestação, parto, contracepção (para citar apenas aqueles que emergiram no contexto das entrevistas) são traduzidos pelos informantes com sentimentos mais difusos. O que faz algumas situações serem consideradas claramente de risco e outras não?

Acredito que seja preciso considerar os impactos para a representação da AIDS como um risco, produzidos pelas campanhas de prevenção e pela divulgação do tema na mídia, com a revelação de histórias de pessoas que contraí- 
ram o vírus HIV nas mais diferentes circunstâncias. Além disso, as doenças sexualmente transmissíveis tradicionais sempre foram também alvo de imaginação pública, associadas que estavam à idéia de uma sexualidade livre e permissiva. A concepção de risco ficou assim atrelada ao campo das doenças.

Contracepção, gestação, parto e os eventos relacionados ao nascimento dos filhos parecem fazer parte de um grupo diferente de experiências. Estas situações estariam relacionadas a projetos de formação de família e à afirmação da identidade adulta mediante a efetivação da paternidade, como bem demonstram as pesquisas de Arilha (1999), junto a jovens e adultos do sexo masculino.

Considerando que ter filhos (reproduzir ou não reproduzir) constitui um aspecto culturalmente reconhecido como próprio da natureza humana (nascemos para procriar), podemos deduzir que por mais preocupação, temor e re cei o que os homens expressem em relação a esses eventos, os mesmos são fundamentais na aquisição de suas identidades sociais. Além do que, tais sentimentos difusos referem-se mais à esfera social dos cuidados e manutenção dos filhos, do que propriamente à fisicalidade, já que eventos reprodutivos são remeti dos à esfera de controle e atribuições femininas. O trabaIho de Heilborn \& Gouveia (1999) menciona, por exemplo, que em setenta entrevistas com mulheres das camadas médias, não é identificada a AIDS espontaneamente quando se fala de prevenção, mas sim o tema da contracepção.

Os depoimentos que ouvi me habilitam a afirmar sobre a existência de uma hierarquia de riscos, que é modificada em função dos atores envolvidos. Nesse caso, quando se trata de pensar nos filhos, especialmente nas filhas, outros riscos entram em cena ou antigos são mais enfatizados. As meninas parecem mais expostas a riscos em saúde reprodutiva (gravidez, violência sexual, doenças sexuais), ao passo que para os meninos são enfatizados riscos de natureza social e urbana. Essa classificação deixa referências de gênero muito claras na forma como percebem os perigos que enfrentam.

Dessa forma, a definição dos riscos a serem evitados ou levados em conta, na linguagem sugerida por Douglas, não se produz ao acaso ou de modo individual, mas é compartilhada na coletividade através dos valores culturais e das instituições sociais que contribuem para a formulação social dos problemas a serem enfrentados por cada sociedade.

Sendo assim, e seguindo a sugestão de Mary Douglas (Douglas \& Wildavsky, 1982), caberia refletir ainda sobre que tipo de valores e contextos sociais, culturais, institucionais dão suporte à esta hierarquia de riscos. Podemos observar que o valor-família e o contexto do casamento, parecem constituir importantes elementos na seleção dos riscos, mesmo para o gênero masculino. Também parecem concorrer para essa definição noções sobre o corpo (em especial a idéia de um corpo higienizado), os gestos e modos (educados). A combinação entre classificações de pessoas segundo a geração e o gênero, por sua vez, contribui para demarcar um grupo (de filhos e filhas) sujeito a riscos específicos, portanto, a um novo arranjo nessa hierarquia. Assim, a hierarquia de riscos parece se modificar dependendo de contextos sociais, culturais, institucionais, históricos e da posição do grupo estudado frente à situação enfocada.

\section{Referências}

ARILHA, M., 1998. Homens: Entre a "zoeira" e a "responsabilidade". In: Homens e Masculinidades: Outras Palavras (M. Arilha, S. Ridenti \& B. Medrado, org.), pp. 51-77, São Paulo: ECOS/Editora 34.

AYRES, J. R.; FRANÇA Jr., I.; CALAZANS, G. \& SALETTI FILHO, H., 1999. Vulnerabilidade e prevenção em tempos de AIDS. In: Sexualidades pel o Avesso: $\mathrm{Di}$ reitos, Identidades e Poder (R. Barbosa \& R. Parker, org.), pp. 49-72, Rio de Janeiro: Instituto de Medicina Social, Universidade Estadual do Rio de Janeiro/São Paulo: Editora 34. 
DOUGLAS, M., 1970. Natural Symbols: Exploration in Cosmology. New York: Pantheon Books.

DOU GLAS, M., 1990. Risk and Blame: Essays in Cultural Theory. London/ New York: Routledge.

DOU GLAS, M. \& WILDAVSKY, A., 1982. Risk and Culture: An Essay on the Sel ection of Technological and Environmental Dangers. Berkeley: University of California Press.

GIDDENS, A.; BECK, U. \& LASH, S., 1997. Modernização Reflexiva: Política, Tradição e Estética na Ordem Social Moderna. São Paulo: Editora UNESP.

GOGNA, M., 1998. Factores psicosociales y culturales en la prevención y tratamiento de las enfermedades de transmisión sexual. Cadernos de Saúde Pública, 14(Sup. 1):81-85.

GOGNA, M. \& RAM OS, S., 1999. Crenças leigas, estereótipos de gênero e prevenção de DSTs. In: Sexualidades pelo Avesso: Direitos, Identidades e Poder (R. Barbosa \& R. Parker, org.), pp. 229-248, Rio de Janeiro: Instituto de Medicina Social, Universidade Estadual do Rio de Janeiro/São Paulo: Editora 34.

GOLDENBERG, M., 1995. A outra: Uma reflexão antropológica sobre a infidelidade masculina. In: A Desconstrução do Masculino (S. Nolasco, org.), pp. 131-147, Rio de Janeiro: Rocco.

GUIM ARÃES, C., 1996. "Mais merece!": O estigma da infecção sexual pelo HIV/AIDS em mulheres. Revista de Estudos Feministas, 4:295-318.

GUIVANT, J. S., 1998. A trajetória das análises de risco: Da periferia ao centro da teoria social. BIB Revista Brasileira de Informação Bibliográfica em Ciências Sociais, 46:3-38.
HEILBORN, M. L. \& GOUVEIA, P., 1999. “Marido é tudo igual": Mulheres populares e sexualidade no contexto da AIDS. In: Sexualidades pel o Avesso: Direitos, Identidades e Poder (R. Barbosa \& R. Parker, org.), pp. 175-198, Rio de Janeiro: Instituto de Medicina Social, Universidade Estadual do Rio de Janeiro/São Paulo: Editora 34.

KNAUTH, D., 1999. Subjetividade feminina e soropositividade. In: Sexualidades pelo Avesso: Direitos, Identidades e Poder (R. Barbosa \& R. Parker, orgs.), pp. 121-136, Rio de Janeiro: Instituto de Medicina Social, Universidade do Estado do Rio de Janeiro/São Paulo: Editora 34.

LOYOLA, M. A., 1994. Percepção e prevenção de AIDS no Rio de Janeiro. In: AIDS eSexualidade: O Ponto de Vista das Ciências Humanas (M. A. Loyola, org.), pp. 19-72, Rio de Janeiro: Relume-Dumará/ Universidade Estadual do Rio de Janeiro.

OLAVARRIA, J., 1999. Desejo, prazer e poder: Questões em torno da masculinidade heterossexual. In: Sexualidades pelo Avesso: Direitos, Identidades e Poder (R. Barbosa \& R. Parker), pp. 153-174, Rio de Janeiro: Instituto de Medicina Social, Universidade Estadual do Rio de Janeiro/São Paulo: Editora 34.

PARKER, R., 1995. A construção social e cultural do risco sexual, ou como fazer pesquisa (em sexualidade) em uma epidemia. Physis, 5:85-98.

SARTI, C., 1996. A Família como Espel ho: Um Estudo sobre a Moral dos Pobres. Campinas/ São Paulo: Editora Autores Associados.

Recebido em 20 de junho de 2000

Versão final reapresentada em 13 julho de 2001

Aprovado em 15 de janeiro de 2002 